\title{
Examining Citizens' Perceived Value of Internet of Things Technologies in Facilitating Public Sector Services Engagement
}

\author{
Ramzi El-Haddadeh \\ College of Business and Economics \\ Qatar University \\ P.O. Box 2713 Doha, Qatar \\ Vishanth Weerakkody \\ Faculty of Management and Law \\ University of Bradford \\ Emm Lane, Bradford \\ BD9 4JL, UK \\ Mohamad Osmani \\ College of Business and Economics \\ Qatar University \\ P.O. Box 2713 Doha, Qatar \\ Dhaval Thakker \\ Faculty of Engineering \& Informatics \\ University of Bradford \\ Bradford BD7 1DP, UK \\ Kawaljeet Kaur Kapoor \\ Brunel Business School \\ Brunel University London \\ Kingston Lane \\ Uxbridge UB8 3PH, UK
}




\title{
Examining Citizens' Perceived Value of Internet of Things Technologies in Facilitating Public Sector Services Engagement
}

\begin{abstract}
With the advancement of disruptive new technologies, there has been a considerable focus on personalisation as an important component in nurturing users' engagement. In the context of smart cities, Internet of Things (IOT) offer a unique opportunity to help empower citizens and improve societies' engagement with their governments at both micro and macro levels. This study aims to examine the role of perceived value of loT in improving citizens' engagement with public services. A survey of 313 citizens in the UK, engaging in various public services, enabled through loT, found that the perceived value of loT is strongly influenced by empowerment, perceived usefulness and privacy related issues resulting in significantly affecting their continuous use intentions. The study offers valuable insights into the importance of perceived value of loT-enabled services, while at the same time, providing an intersectional perspective of UK citizens towards the use of disruptive new technologies in the public sector.
\end{abstract}

Keywords: Internet of Things, Public Sector, Perceived Value, Continuous Use

\section{Introduction}

Applications of the Internet of Things (IOT) related technologies in the public sector has been a common feature in 'smart cities' context. Among many definitions of 'smart cities' (Albino et al., 2015), two definitions closer to our work are by Cretu (2012): "smart cities are all about networks of sensors, smart devices, real-time data, and ICT integration in every aspect of human life" and by Harrison et al. (2010): "smart city denotes an instrumented, interconnected and intelligent city". Instrumented refers to the capability of capturing and integrating live, realworld data using sensors, meters, appliances, personal devices, and other similar sensors. From a technical perspective, the IoT applications in smart cities typically involve pervasive sensing, sensing data collection, real-time use of data, and data analytics (Reaidy et al. 2015). The advances in smart cities development are aimed largely at improving the quality of life for 
citizens and enhancing the value derived from public services through use of internet based devices (Kim et al., 2017). The manifestation of sociological nuances in the implementation of IoT based developments means that cities adopting these developments will be encouraging their citizens to engage with public services in ubiquitous ways to engage within their communities (Kshetri 2017).

In the context of the UK, the government having realised the potential positive impact that IoT related technology can have on UK society, has initiated an investment of more than $f 45$ million (The Government Office for Science, 2014). According to the former UK Prime Minster, David Camron, "The Internet of Things is a transformative development. Technologies that could allow literally billions of everyday objects to communicate with each other over the Internet have enormous potential to change all of our lives. These technologies are a way of boosting productivity, of keeping us healthier, making transport more efficient, reducing energy needs and making our homes more comfortable". However, Gunashekar et al. (2016) argues that to maintain the anticipated evolution and development of IoT ecosystems in the UK, citizens will need to be at the core of these development in order to deliver the required socio-economic benefits. While there is very little empirical evidence to conceptualise self-sustained, intelligent and interconnected cities as defined by Harrison et al. (2010), to our knowledge no studies exist which have examined the influence loT has on citizens' engagement with public services that are enabled through loT based technologies and/or applications within a smart city context. Moreover, there is no evidence presently on the influence that perceived value has on citizens' use of loT enabled services within the public sector. This is particularly relevant for the UK context where huge investments in new technologies in the public sector have often failed to deliver anticipated outcomes (Waller and Weerakkody, 2016; Omar et al., 2017). The above arguments verifies the need to further examine the value of utilising loT enabled technologies to help to further improve citizens engagement and participation in public sector services.

Although it is evident that loT technologies offer opportunities for citizens to be more engaging in various activities within their communities, the perceived value of such technologies is yet to be appreciated among them. In this respect, often their engagement appears mostly to be constrained to a passive one with little attempts to move beyond to a more proactive role. 
Hence, this study attempts to examine the reasons for citizens to appreciate the perceived value of IoT in order to continue to use IoT enabled public services. In other words, this study attempts to address the following research question: what are the determinants affecting the perceived value of internet of things enabled public services in facilitating citizens' engagement? In order to answer the research question set out above and realise the aim of this study, it starts the debate by offering literature insights on the use of IOT in the context of public services. In this context, antecedents related to citizens' behavioural aspects associated with innovative technologies, namely IoT, in the public sector are carefully examined. While few studies have examined role of loT adoption (Mital et al., 2017, Hsu and Lin, 2016), no previous study has empirically examined the associated adoption and use factors from a public sector perspective. Furthermore, this study explicitly examines the role of citizen' empowerment and information privacy, through perceived value, as well as social support on loT use within a public sector context. The remainder of this paper is organized as follows: Section two provides a theoretical perspectives on loT in the public sector domain. This is followed by the proposed research model and research hypotheses developed to test the model in section three. Section four presents the methodological approach utilised in the study while the analysis of the empirical findings are presented is section five. Section six presents the discussions and the key findings of the paper. Finally, section seven offers some conclusive remarks and associated implications for both practitioners and researchers.

\section{Internet of Things and Smart Cities for Public Services: Benefits and Challenges}

There have been considerable number of public services delivery applications using loT. Among these, Air quality monitoring is one of the earliest and most widely used in the UK. These applications allow monitoring of air quality in crowded areas, parks or fitness trails (Al-Ali 2010; Penza et al. 2014). The EU2020 energy directive has set out legislation to cut $20 \%$ greenhouse emissions and encourage renewable energy to drive energy efficiency in cities. IoT systems development often complements these policies on air quality monitoring. For example, Jain et al., (2016) found that vehicle pollution was a less significant factor in overall pollution levels 
during research done to monitor air pollution using loT based sensors. Another common application of loT is to monitor noise. Noise Monitoring applications help with the real-time monitoring of noise produced at a particular time (Maisonneuve et al. 2009) and aid security, and traffic monitoring. For example, noise monitoring algorithms can detect any unusual sounds such as brawl or crashes. Research by Wang et al. (2013) explored the use of noise sensors and back propagation neural network to simulate road traffic noise of 100 roads in Xiamen Island in China based on the data collected in 35 roads. Similarly, traffic monitoring systems are often designed in conjunction with noise and air quality monitoring, and using the sensing and GPS capabilities in modern vehicles (Li et al. 2009). Traffic congestion is a severe problem in most countries, and IOT applications offer a great potential in aiding the development of solutions to this problem. A smart city project in Vietnam combines sensors such as mobile communication networks (GSM, 3G), positioning systems (GPS), RFID, specialized sensors, and video cameras for traffic monitoring (Cao et al. 2016). The project in Da Nang city combines these sensors with weather sensors to control the city's traffic lights according to traffic flow (Kshetri 2017). An extension of the traffic monitoring applications is smart parking and smart lighting applications. Smart parking applications utilise road sensors and intelligent displays to direct motorists along the best path for parking in the city. For example the SmartSantander smart city project in the Spanish city of Santander utilises ferromagnetic wireless sensors buried under the asphalt at parking bays to aggregate data from the sensors and present this information on screens. This information is also provided as part of a mobile app for navigation purposes. Historical data further helps councils to plan for parking provisioning (Sanchez, 2014). Street lighting applications focus on the use of IoT devices to manage street lamp intensity according to the time of the day, the weather condition, and the presence of people (Zanella et al., 2014).

Another growing used of IOT applications is in agriculture. There use here is aimed at helping farmers to improve farming practices and to support better crop production. Sensors are used for controlling temperature, nutrient, and water flow. In addition, various sensors are used for monitoring soil and weather conditions. Such monitoring is often combined with air quality monitoring for improving quality of the plants (Kshetri 2017). Collective Intelligence Agriculture 
(Cl-Agriculture) project in Indonesia utilised a similar set-up to advise farmers on the best time to plant, fertilise, and use pest control. Ez-Farm project in Kenya, employs water tanks, soil moisture and infrared light sensors to monitor the health of the farms (Olubiyo et al. 2017). In Vietnam loT systems are used to monitor intrusion of saltwater in agricultural land (Cao et al. 2016). There are other significant projects involving loT including on food safety (Cao et al. 2016) and monitoring of end-to-end milk production (Kshetri 2017). Water quality and Wastewater management is another connected area where IoT applications that utilise sensors can be used to measure various elements (for example, $\mathrm{pH}$, salt, phosphorus, turbidity, salinity, pH, chlorine, and conductivity) in water (Cao et al., 2016; Wng et al., 2013; Xue 2012 and Boulos, 2014). In recent times, the application of IoT in health (Yang et al. 2014), smart grid (Bonomi et al. 2012), and infrastructure monitoring (Zanella et al. 2014, Thakker et al. 2015) has continued to evolve.

While there are many applications of IoT in the public sector context, the technical challenges in developing IOT applications for public services delivery are many and revolve around: interoperability, heterogeneity, integration, and optimising battery consumption. Devices Heterogeneity and Interoperability challenges are linked to the pace of loT development. The loT systems development stack is still evolving at a rapid pace and currently without any prominent and widely agreed architectures or technology solutions. Hence, one of the leading challenges in developing loT applications in public services is the non-interoperability of the heterogeneous technologies currently used in city and urban developments (Zanella et al. 2014). Nonetheless, it became evident that there has been a lack of standardization of loT device models with many competing standards. This makes interoperability a difficult challenge (Mineraud 2016). Linked to this is Data Heterogeneity and Integration where loT applications require systems to combine volumes of heterogeneous data from diverse sources to determine relevant features, interpret and compare data and their relationships to support decisionmaking (Chen et al. 2014). According to a study conducted by Mineraud (2016), there are more than 40 credible loT platforms for data engineering and analytics in the market; however majority follow non-uniform data formats. 
Another key challenge linked to new innovations such as loT is availability where citizens can utilize these innovations securely and reliably (Misra et al. 2015). Security of loT applications is a complex technical challenge due to the involvement of multiple devices, services, cloud and networks in their development. IoT devices are often located in public places opening them up to additional physical security challenges. These devices are also less powerful and resourceconstrained (Whitmore et al. 2015) requiring low cost, low latency, and energy-efficient cryptography algorithms and related flexible hardware. Also, authentication is vital for secure applications hence ensuring that loT devices are identifiable (Mahalle et al. 2013). There are already existing studies highlighting security concerns around the use of existing IoT applications, many in public services (Enterprise, 2015; Barcena 2015; McDermid, 2015; Lheurex 2016). In this respect, the issue of data ownership and management is a critical factor in the engagement of citizens with loT (Whitmore et al., 2015).

While the main benefits and challenges of the diffusion and use of IoT are documented in the existing literature, the normative literature on the adoption of IoT is still continuing to emerge. From our literature review, several noteworthy recent studies include research by Lee and Lee (2015), Hsu and Lin (2016), Hwang et al. (2016), Mital el al. (2017), Hsu and Yeh (2017). In their study Lee and Lee (2015) verified how successful adoption of IOT in an organisational sittings and contribute positively towards improving the overall value for customers in these organisations. Furthermore, Hsu and Lin (2016) examined network externalities on consumers' IoT adoption. Interestingly, Hwang et al. (2016) pointed out that the challenges of adoption are yet to be fully explored. In their study, they pointed out that "The expected rapid adoption and diffusion of Internet of Things technologies has not yet taken place due to lack of understanding." Moreover, Mital el al (2017) examined consumers' adoption of loT based healthcare monitoring devices through utilising TAM, TBP and TRA models in the context of India. Additionally Hsu and Yeh (2017) offered an organisational perspective through evaluating loT adoption in a decision-making context within the logistics industry. Worth noting here is the fact that these studies have all focused examining the fundamentals of IoT adoption from consumers and organisational perspective rather than specifically focusing on understanding citizens' viewpoint. Nonetheless, technology adoption models such as TAM has been criticized 
for not considering behavioural intention in the contexts of complex relationships that involve perceptions relating to prior use (Taylor and Todd, 1995). The simple antecedents in TAM model i.e. usefulness and ease of use are insufficient to explain a complex situation because there are no antecedent components helping to explain the previous users relationships (Chan and Lu, 2004). Sun \& Zhang (2006) also declared a weakness in explanatory aspects and inconsistencies among these antecedents. Similarly, the UTAUT emphases on adoption of technology in terms of different technologies; therefore, it does not explain the users' expectations and their beliefs that may have occurred in the continuation process of ICT usage (Venkatesh et al., 2011). Further, the UTAUT model focuses on expectation performance rather than personal expectation; therefore, it is out of the traditional users (citizens) scope and only fits with work-place environments. Venkatesh also recommended further studies on identifying constructs that can add to the prediction of intention and behaviour to their model.

\section{Theoretical development and hypotheses}

This study proposes an acceptance model for loT smart devices in the context of public sector services (figure 1). The model aims to report the technological, social, personal, and contextual attributes influencing citizens' use. This model examines the technological aspects by employing perceived usefulness, which is often accompanied with key drivers of e-commerce, such as information privacy to account for associated risks (for instance, Pavlou, 2003). In addition, citizens' empowerment will be evaluated to understand if the use of loT smart devices drives personal change, and improves the overall quality of life for the citizens. The model also accounts for the social perspective by assessing the available social support. Earlier research suggests that perceived value and social support are integral contextual elements motivating online community participation (Hajli et al., 2015), which have been incorporated in the proposed model. In summary, the integrated model proposed in this study investigates the role of perceived value in facilitating citizens' engagement of IoT related technologies on continued use intentions to engage in public sector services. 


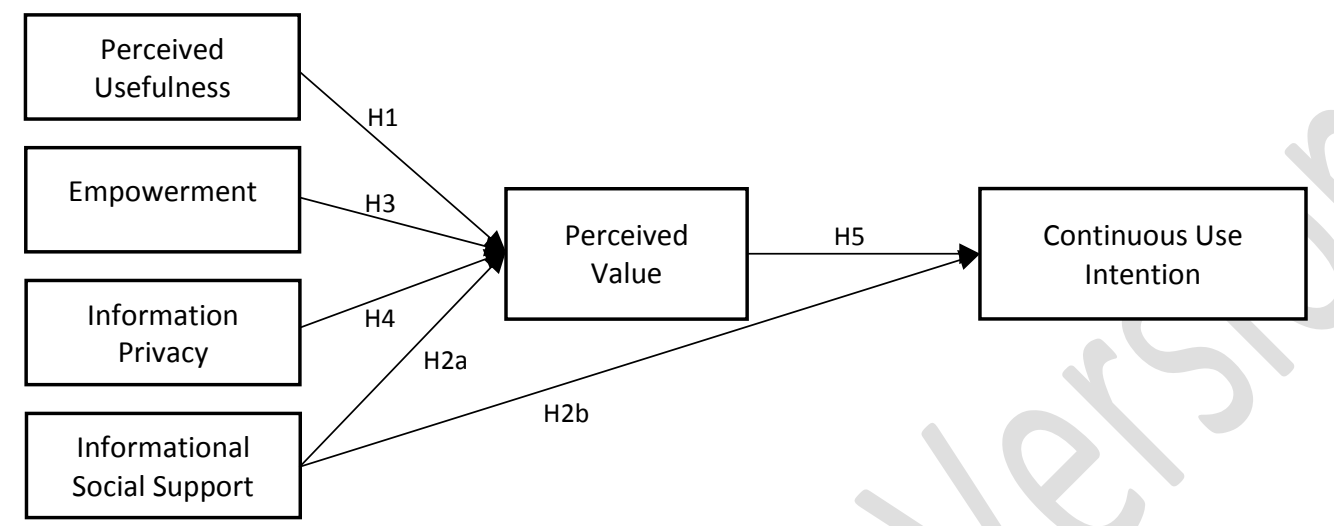

Figure 1 Proposed model

\section{Perceived Usefulness}

Gao and Bai (2014) identify lack of clear communication of loT benefits to potential users as one of the critical reasons behind the slow acceptance rate of loT related applications. The biggest advantage of loT comes with its aim to connect billions of sensors to the Internet to effectively and efficiently manage information and resources to build smarter cities (Perera et al., 2013). Existing literature on loT related devices have reported a significant influence of perceived usefulness on use (for instance, Choi and Kim, 2016; Gao and Bai, 2014; Prayoga and Abraham, 2016). Essentially, the loT smart devices enable users to use their smart phones and other smart devices to ubiquitously gather real-time information affecting lives on a daily basis. Thereby, loT enabled smart devices can obviously add benefit to citizens (Pura, 2005; Trimi \& Sheng, 2008) and greatly enhance their perceived value. Therefore, this study proposes the following hypothesis,

H1: Perceived usefulness of loT enabled public services that users use smart devices to access positively influences citizens' Perceived value of public services.

\section{Informational Social Support}


Literature recognizes social support as an integral component driving participation in online communities (Hajli et al., 2015). Online interactions are elusive and dependent on virtual exchange of messages that increase the significance of informational support in Internet communications (Huang et al., 2010). According to Liang et al. (2011), support on a social platform facilitates warmth, and the consequent satisfactory experience results in user satisfaction from social interactions. Hence, such support can positively influence the continued use intentions. Hajli et al (2015) also reported a significant effect of social support on continuance participation intentions in online communities. Within this study, citizens' use of available information to engage in public sector services using loT devices is not expected to be without obstacles. Employing this construct can help assess the quality of information available, alongside the ready informational support resulting in enhancing citizens value (Hajli et al., 2015). It is thus hypothesized as follows,

H2a: Informational social support will positively influence citizens' perceived value of loT enabled public services

H2b: Informational social support will positively influence citizens' continuous use intention for loT enabled public services

\section{Empowerment}

Empowerment is a construct that measures perceived influence of consumer willingness to participate in the design of a product/services and consequent decision-making (Spreitzer, 1995). Evidence in the literature suggest the use of this construct in consumer research for evaluating consumer empowerment in direct relation to information access and other available choices for the consumers (Conrad Henry and Caldwell, 2006; Tiu Wright et al., 2006). Given that this study examines citizens' perceived value of using loT enabled public services, empowerment can help in offering more insights towards verifying how citizens can realize their engagement can effectively contribute towards drawing individual and societal benefits. Both, information systems and consumer research position Internet as a technology facilitating enhanced empowerment in reinforcing individual identity and increasing efficiencies (Füller et 
al., 2010). When users experience a feeling of competence in successfully using a particular service, they feel empowered resulting in creating value for them (Bandura, 1977; Bagozzi and Dholakia, 2006; Füller et al., 2010; Porter and Donthu, 2008). This construct will thus be examined for its influence on perceived value to enrich the line of research on loT related technologies.

H3: Empowerment has a positive influence on citizens' Perceived Value of IOT enabled smart devices in a public sector context

\section{Information Privacy}

Information privacy concerns refer to citizen concerns related to the collection and use of personal information by online businesses (Son and Kim, 2008). Malhotra et al (2003) identify users' limited confidence in online information privacy as a critical factor impeding the growth of e-commerce. Studies like Dinev and Hart (2003) report that despite privacy concerns inhibiting the use of e-commerce, personal interest and Internet trust can outweigh privacy risk perceptions. Research verified that security is often the first element considered by users before using a new system (Fang et al., 2006). However, in cases of personal information misuse, online users are highly likely to publicly report and share negative experiences to stop using, and prevent friends, family and others from using such services (Son and Kim, 2008). Studies like Kowatsch and Maass (2012) have reported that privacy concerns about loT services have a significant influence on user intentions. In this respect, various studies emphasized on the role of service providers and government regulators in offering assurances as a safeguard for users to maintain the required acceptance and adoption of loT technologies (Ziegeldorf et al., 2014; Vermesan et al. 2011; Miorandi et al. 2012; Chui et al., 2010). Hence, in the context of public sector services, by obtaining the required assurances to address such concerns for relevant government agencies and/or service providers, citizens are more likely to use IoT enabled services. This construct can thereby be hypothesized as follows, 
H4: Service providers addressing citizens' information privacy concerns will have a positive influence on their perceived value of loT enabled smart devices in a public sector context

\section{Perceived Value}

Interestingly, existing literature suggests that the TAM construct, perceived usefulness, is closely related to perceived value (Pura, 2005). Other studies like Yang and Peterson (2004) suggest perceived value finds its roots in equity theory, which focuses on the consumer's input and output ratio. According to Zeithaml (1988) consumers associate perceived value with the overall assessment of product utility, by specifically evaluating the give and take involved in the process. The give factor can be non-monetary and evaluated in terms of the time and effort invested in using a product or service (Dodds et al., 1991). Literature reports positive effect of perceived value on continued use intentions (Chen and Chen, 2010; Hajli et al., 2015). Nonetheless, there is limited evidence in the literature on the relationship shared by perceived value, and continued use intentions in the context of loT related technologies. This study thus examines perceived value to account for the influence of non-monetary factors involved in using loT smart devices on citizen use and continued use intentions. It has been hypothesized as follows,

H5: Increased perceived value will have a positive influence on citizens' continued use intentions towards IoT enabled smart devices in a public sector context.

\section{Methodology}

This study follows a deductive approach staring with the theory and leading to research hypothesis and thereafter confirming or rejecting the hypotheses (Collis and Hussey, 2014; Bryman and Bell, 2011). Since this study follows positivist methodology and deductive approach; survey method is the most appropriate for the purpose of this study (Collis and Hussey, 2014). To ensure the reliability and validity of all variables in the model, the survey 
instruments were based on the results of the previous studies. All of the constructs were measured using a seven-point Likert scale anchored at $1=$ strongly disagree and $7=$ strongly agree. Appendix 1 shows the survey instruments and its sources. The surveys were distributed electronically to citizens and targeted the users of IoT services by using filtered questions for the purpose of this study. To do so, the authors relied on various social media outlets including LinkedIn, Facebook, Twitter in attempt to reach out to UK based IoT users. The survey targeted IoT users who have experienced the use of such technology within their daily lives; specifically in the context of public services. They were offered few examples to help them in realising the targeted services. Examples of citizens' engagement with such information and services through IoT include the use of smart phones and smart meters/devices to collect real-time information about the consumption of domestic utilities such as electricity and gas monitoring of personal health and wellbeing related information, real time pollution, noise levels, traffic and transport updates and augmented reality. Before distributing the questionnaire, a pilot study was conducted to test the reliability and validity of the survey items based on the results of 28 completed questionnaires from the targeted respondents. From this effort, the study collected 350 responses from across the UK. After data cleaning, a total of 313 questionnaires was considered for analysing the research hypotheses. This study used the Structural Equation Modelling (SEM) technique in Analysis of Moment Structures (AMOS) to validate the hypotheses and the performance of the proposed conceptual model. It helps to test statistically the hypothesized model in a simultaneous analysis of the entire system of variables to determine the extent to which it is consistent with the data. SEM was considered for this study since it fits the purpose of testing the hypotheses that involve multiple regression analysis among a group of dependent and independent variables (Hair et al., 2010).

\section{Research Findings}

\section{Demographic Profile}

Table 1 presents the demographic data obtained from the respondents. The results highlights the average respondent's age ranges from 25 to 74, with males accounting for $48.2 \%$ and females $51.8 \%$ of the sample. The majority of the respondents (62\%) were diploma or bachelor 
degree holders and over $80 \%$ of the sample used smart phones to collect information. Majority of the respondents have used loT enabled smart devices for over 36 months and $36.4 \%$ of the population used IoT smart devices several times a day to collect information. One of the most common uses of loT enabled smart devices was to collect real time information about weather (82.4\%) and Transport services (69.3\%).

Table 1: Respondents' Demographic Profile

\begin{tabular}{|c|c|c|c|}
\hline & & Frequency & Percentage \\
\hline \multirow{6}{*}{ Age } & $18-24$ & 22 & 7 \\
\hline & $25-34$ & 44 & 14.1 \\
\hline & $35-44$ & 47 & 15 \\
\hline & $45-54$ & 58 & 18.5 \\
\hline & $55-64$ & 61 & 19.5 \\
\hline & 65 and above & 81 & 25.9 \\
\hline \multirow{2}{*}{ Gender } & Male & 151 & 48.2 \\
\hline & Female & 162 & 51.8 \\
\hline \multirow{3}{*}{$\begin{array}{l}\text { Technologies used for } \\
\text { collecting information }\end{array}$} & Smart phones & 250 & 79.9 \\
\hline & Tablets & 205 & 65.5 \\
\hline & Smart Watch & 26 & 8.3 \\
\hline \multirow{5}{*}{ Type of services } & Health and wellbeing services & 134 & 42.8 \\
\hline & Transport services & 217 & 69.3 \\
\hline & $\begin{array}{l}\text { Domestic utilities related } \\
\text { services }\end{array}$ & 159 & 50.8 \\
\hline & Weather & 258 & 82.4 \\
\hline & Augmented reality services & 62 & 19.8 \\
\hline
\end{tabular}

\section{Descriptive Statistics}

Table 2 presents the mean and standard deviation for all the items. All items were rated on a seven point Likert scale with a score of 7 indicating strongly agree and a score of 1 indicating a strong disagree. The mean score for all items of the constructs show a mean of greater than the neutral point (4) which points out that respondents mostly agreed with the items. It can be noted that empowerment construct was initially measured with three items; E1, E2, and E3. Nonetheless, item E3 was removed based on insignificant factor loading measure, while at the same time E1 and E2 items were noticed to be highly correlated to each other. Hair et al. (2010) verified that initial confirmatory factor analysis can indicate the need for further refinement of the model when relevant model fit indices have inadequate values (i.e. below the minimum 
recommended criteria). Therefore, in the developed model and for this specific construct, a refinement of the model was carried out by removing E3 item resulting in an improved model fit.

Table 2 also shows that the Cronbach's alpha for all the constructs is above 0.83, confirming that the data is highly reliable and there is internal consistency of the scales. Cronbach's alpha with a figure of $\geq 0.90$ is considered excellent reliability, $0.70-0.90$ is considered high reliability, 0.50-.70 is moderate reliability, and $\leq 0.50$ is low reliability (Hinton et al., 2004).

Table 2: Descriptive Statistics

\begin{tabular}{|c|c|c|c|c|c|c|c|}
\hline \multicolumn{8}{|c|}{ Descriptive Statistics } \\
\hline & $\mathrm{N}$ & Minimum & Maximum & Mean & Std. Deviation & Cronbach Alpha & No of Items \\
\hline E1 & 313 & 1 & 7 & 4.66 & 1.230 & \multirow{2}{*}{0.830} & \multirow[b]{2}{*}{2} \\
\hline E2 & 313 & 1 & 7 & 4.42 & 1.309 & & \\
\hline IFS1 & 313 & 1 & 7 & 4.35 & 1.284 & \multirow{3}{*}{0.886} & \multirow{3}{*}{3} \\
\hline IFS2 & 313 & 1 & 7 & 4.28 & 1.278 & & \\
\hline IFS3 & 313 & 1 & 7 & 4.32 & 1.315 & & \\
\hline CUI1 & 313 & 1 & 7 & 5.10 & 1.156 & \multirow{3}{*}{0.917} & \multirow{3}{*}{3} \\
\hline CUI2 & 313 & 1 & 7 & 5.09 & 1.130 & & \\
\hline CUI3 & 313 & 1 & 7 & 4.95 & 1.246 & & \\
\hline PV1 & 313 & 1 & 7 & 5.19 & 1.324 & \multirow{3}{*}{0.875} & \multirow{3}{*}{3} \\
\hline PV2 & 313 & 1 & 7 & 5.24 & 1.251 & & \\
\hline PV3 & 313 & 1 & 7 & 5.27 & 1.185 & & \\
\hline IP1 & 313 & 1 & 7 & 6.32 & 1.163 & \multirow{5}{*}{0.951} & \multirow{5}{*}{5} \\
\hline IP2 & 313 & 1 & 7 & 6.33 & 1.170 & & \\
\hline IP3 & 313 & 1 & 7 & 6.32 & 1.121 & & \\
\hline IP4 & 313 & 1 & 7 & 6.37 & 1.111 & & \\
\hline IP5 & 313 & 1 & 7 & 6.14 & 1.103 & & \\
\hline PU1 & 313 & 1 & 7 & 4.82 & 1.251 & \multirow{3}{*}{0.854} & \multirow{3}{*}{3} \\
\hline PU2 & 313 & 1 & 7 & 4.84 & 1.233 & & \\
\hline PU3 & 313 & 1 & 7 & 4.94 & 1.083 & & \\
\hline
\end{tabular}

\section{Confirmatory Factor Analysis}

The measurement model was tested using Confirmatory factor analysis. As suggested by Hair et al. (2006), this study has validated its confirmatory factor analysis through two stages: (1) goodness of fit indices and (2) Construct Validity. To conduct the first stage, this study has used 7 goodness of fit indices (Hair et al., 2010), Chi square to $\left(X^{2}\right)$ to the degree of freedom (Df), goodness of fit index (GFI), adjusted goodness of fit index (AGFI), incremental fit index (IFI), Tucker-Lewis Index (TLI), comparative fit index (CFI), and root mean square error of approximation (RMSEA). The fit statistics are reported in Table 3. The table indicates that all the 
figures illustrate a good fit for the measurement model. $X^{2} / \mathrm{df}$ has achieved an acceptable fit of 1.837 and is well above the minimum requirement of (1:3). The results for GFI, IFI, TLI, CFI were $0.923,0.977,0.971,0.977$ respectively and all were above the recommended value of $\geq 0.9$. The results for AGFI indicated a figure of 0.893 , which met the recommended criteria of $\geq$ in 0.80. RMSEA has also met the recommended criteria of $<0.80$ and achieved an acceptable figure of 0.052 .

Table 3: CFA Model Estimates

\begin{tabular}{|l|c|c|}
\hline Model Fit Indices & Recommended Criteria & Default Model \\
\hline Chi-square & & 251.603 \\
\hline Degree of freedom & & 137 \\
\hline $\mathrm{X}^{2} / \mathrm{df}$ & $>3$ & 1.837 \\
\hline GFI & $\geq 0.90$ & 0.923 \\
\hline AGFI & $\geq 0.80$ & 0.893 \\
\hline IFI & $\geq 0.90$ & 0.977 \\
\hline TLI & $\geq 0.90$ & 0.971 \\
\hline CFI & $\geq 0.90$ & 0.977 \\
\hline RMSEA & $<.080$ & 0.052 \\
\hline
\end{tabular}

For the second stage, this study has validated the CFA results through convergent and discriminant validity. The construct validity statistics are reported in Table 4 . Convergent validity is assessed by average variance extracted and composite reliability, and the rule of thumb is that AVE value should be greater than 0.5 and composite Reliability should be greater than 0.70 (Bagozzi and $Y i, 1988$ ). The results of our study indicate a high level of convergent validity for all the latent constructs used in the measurement model. The results show a significant level of discriminant validity, as AVE is greater than the squared correlation estimate for all the constructs.

Table 4: Convergent and Discriminant Validity of Constructs

\begin{tabular}{|l|c|c|c|c|c|c|c|c|c|c|}
\hline & CR & AVE & MSV & MaxR(H) & IFSS & PV & Info_P & Trust & EMPR & CUI \\
\hline IFSS & 0.892 & 0.735 & 0.379 & 0.917 & $\mathbf{0 . 8 5 7}$ & & & & & \\
\hline PV & 0.883 & 0.718 & 0.445 & 0.958 & 0.342 & $\mathbf{0 . 8 4 7}$ & & & & \\
\hline Info_P & 0.952 & 0.799 & 0.255 & 0.979 & 0.046 & 0.505 & $\mathbf{0 . 8 9 4}$ & & & \\
\hline PU & 0.861 & 0.675 & 0.514 & 0.982 & 0.512 & 0.618 & 0.305 & $\mathbf{0 . 8 2 1}$ & & \\
\hline EMPR & 0.832 & 0.712 & 0.514 & 0.983 & 0.616 & 0.595 & 0.116 & 0.717 & $\mathbf{0 . 8 4 4}$ & \\
\hline CUI & 0.919 & 0.791 & 0.514 & 0.986 & 0.415 & 0.667 & 0.324 & 0.640 & 0.717 & $\mathbf{0 . 8 9 0}$ \\
\hline
\end{tabular}




\section{Structural Model Testing}

After the validity of CFA, the next stage is to test the structural model to confirm the relationships between the factors as hypothesized. Similar to CFA, this study has tested the Structural model using $\mathrm{X}^{2} / \mathrm{df}, \mathrm{GFI}, \mathrm{AGFI}, \mathrm{IFI}, \mathrm{TLI}, \mathrm{CFI}$ and RMSEA. Table 5 illustrates the results for the Structural model and it indicates that all the figures illustrate a good fit for the measurement model. $\mathrm{X}^{2} / \mathrm{df}$ has achieved an acceptable fit of 2.268 and is well above the minimum requirement of (1:3). The results for $\mathrm{GFI}, \mathrm{IFI}, \mathrm{TLI}, \mathrm{CFI}$ were $0.905,0.964,0.956,0.964$ respectively and all were above the recommended value of $\geq 0.90$. The results for AGFI indicated a figure of 0.873 , which met the recommended criteria of $\geq$ in 0.80 . RMSEA has also met the recommended criteria of $<0.80$ and achieved an acceptable figure of 0.64 .

Table 5: Model Fit indices for Structural Model

\begin{tabular}{|l|c|c|}
\hline Model Fit Indices & Recommended Criteria & Default Model \\
\hline Chi-square & & 319.839 \\
\hline Degree of freedom & & 141 \\
\hline $\mathrm{X}^{2} / \mathrm{df}$ & $\geq 3$ & 2.268 \\
\hline GFI & $\geq 0.90$ & 0.905 \\
\hline AGFI & $\geq 0.80$ & 0.873 \\
\hline IFI & $\geq 0.90$ & 0.964 \\
\hline TLI & $\geq 0.90$ & 0.956 \\
\hline CFI & $<.080$ & 0.964 \\
\hline RMSEA & & 0.64 \\
\hline
\end{tabular}

After establishing the goodness of fit for the structural model, the research hypotheses are tested by analysing the path significance of each relationship. Table 6 is presenting the results of path estimates and the results support four hypotheses and rejects one. Path estimates is tested using standardised estimate, critical ratios ( $t$-value) and $p$-value and a relationship is significant when a t-value is above 1.96 and a $p$-value is $\leq .05$. The results supported $H 1, H 2 b$, $\mathrm{H} 3, \mathrm{H} 4$ and $\mathrm{H} 5$ and rejected $\mathrm{H} 2 \mathrm{a}$ as the t-values is below 1.96 and a p-value of greater than .05. Figure 2 presents the conceptual model for this study using structural equation modelling technique of AMOS. From the proposed model, the results revealed that the continued intention to use IoT services can be predicted by the proposed model $\left(R^{2}=0.52\right)$. Additionally, the results verified that perceived value can be determined by the proposed model with a 
variance of $R^{2}=0.59$. The results indicate that perceived usefulness, empowerment and privacy concerns have positive impact on perceived value with path coefficients of $0.39,0.23$ and 0.45 respectively, thus supporting $\mathrm{H} 1, \mathrm{H} 3$ and $\mathrm{H} 4$. On the other hand, informational social support has negative impact on the perceived value with a path coefficient of -0.8 and thus rejecting H2a. Nonetheless, informational social support has positive impact on continuous use intention with path coefficients of 0.22 . Finally, perceived value has a positive impact on continuous use intention with a path coefficient of .61 and supporting H5. Overall, the path coefficients figures supported four hypotheses ( $\mathrm{H} 1, \mathrm{H} 2 \mathrm{~b}, \mathrm{H} 3, \mathrm{H} 4$, and $\mathrm{H} 5)$ and rejected $\mathrm{H} 2 \mathrm{a}$.

Table 6: Path Hypothesis Testing

\begin{tabular}{|c|l|c|c|c|c|c|}
\hline Hypotheses & \multicolumn{1}{|c|}{ Variables } & Estimate & S.E. & C.R. & $\begin{array}{c}\text { P } \\
\text { value }\end{array}$ & Finding \\
\hline $\mathrm{H} 1$ & Perceived Usefulness $\rightarrow$ Perceived Value & .228 & .079 & 2.875 & .004 & Supported \\
\hline $\mathrm{H} 2 \mathrm{a}$ & $\begin{array}{l}\text { Information Social Support } \rightarrow \text { Perceived } \\
\text { Value }\end{array}$ & -0.040 & .048 & -.825 & .409 & $\begin{array}{c}\text { Not } \\
\text { Supported }\end{array}$ \\
\hline $\mathrm{H} 2 \mathrm{~b}$ & $\begin{array}{l}\text { Information Social Support } \rightarrow \text { Continuous Use } \\
\text { Intention }\end{array}$ & .195 & .045 & 4.370 & $* * *$ & Supported \\
\hline $\mathrm{H} 3$ & Empowerment $\rightarrow$ Perceived Value & .358 & .076 & 4.681 & $* * *$ & Supported \\
\hline $\mathrm{H} 4$ & Information Privacy $\rightarrow$ Perceived Value & .409 & .057 & 7.123 & $* * *$ & Supported \\
\hline $\mathrm{H} 5$ & Perceived Value $\rightarrow$ Continuous Use Intention & .757 & .073 & 10.427 & $* * *$ & Supported \\
\hline
\end{tabular}




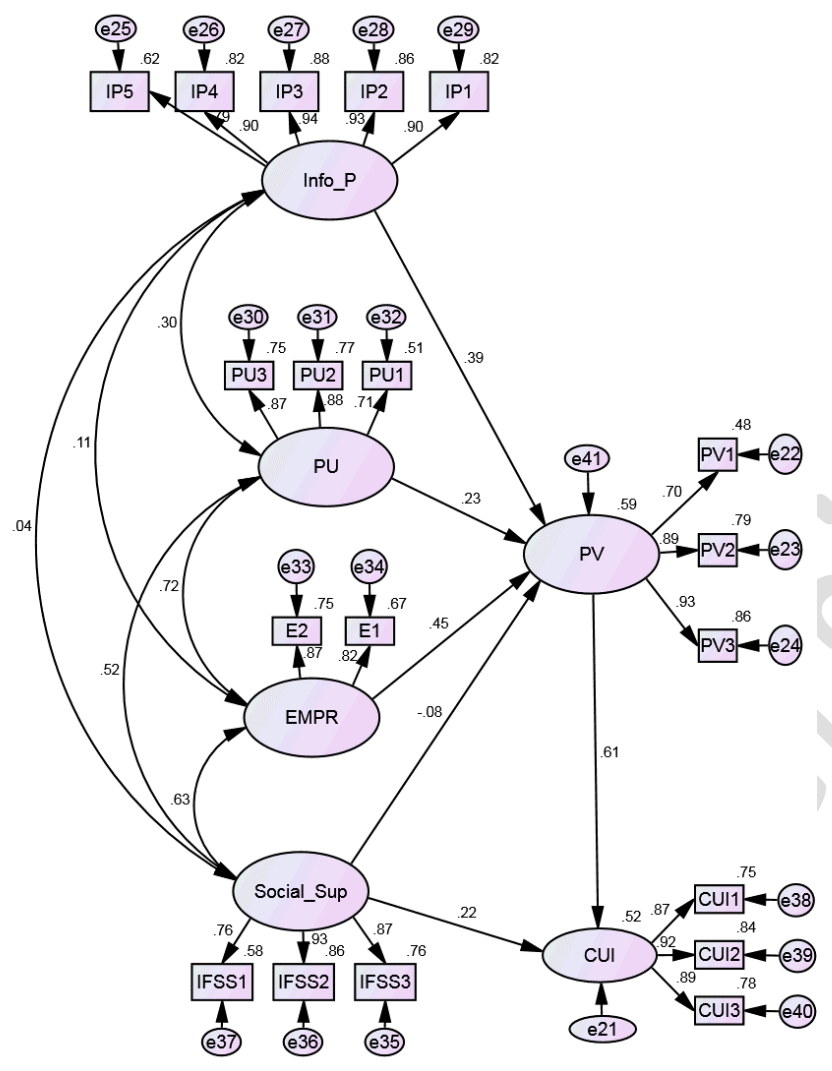

Figure 2: Path Coefficient for Structural Model using AMOS

\section{Discussion}

Results from the empirical findings in this study reveal that perceived value can play a key role in affecting citizens' decision in continuing to use loT enabled services offered by the public sector. The study explains that usefulness, service provider assurances of information privacy, and citizen empowerment influence citizens' perceived value which in return will ultimately influence continuous use intentions of these services. Additionally, while informational social support significantly and directly affected continued intention to use loT enabled public sector services, the findings verified that perceived value have an impact on citizens' continuous intention to use. Reflecting on the literature, Hsu and Lin (2016) and Atzori et al. (2010) emphasised on the importance of users realising benefits, including usefulness of how loT can contribute positively towards improving their quality of life across various service domains. Similarly, in the context of public sector, citizens will need to foresee value in utilising loT enabled devices to continuously engage in public sector services. 
In determining the significant factors influencing citizens' perceived value for loT enabled public services, the results verified three key determinates: namely, citizens' empowerment, information privacy and usefulness. With respect to empowerment, the positive influence obtained from the empirical work verify that when citizens experience a feeling of competence in successfully using an loT enabled service, they feel empowered resulting in creating value for them. This is consistently in line with previous studies which emphasized on how empowerment can positively contribute towards creating value for users when using technological innovations (Bandura, 1977; Bagozzi and Dholakia, 2006; Füller et al., 2010; Porter and Donthu, 2008). Further, our results have also confirmed information privacy for loT facilitated public services can have a positive impact on their perceived value when assurances are offered by the relevant service providers and government regulators. While the literature emphasized on how information privacy concerns can negatively influence users value perception of loT enabled services, studies also confirmed assurances by service providers and government regulators can offer the required encouragement and guarantees in realising the value and facilitating use (e.g. Ziegeldorf et al., 2014; Vermesan et al. 2011; Miorandi et al. 2012; Chui et al., 2010). Finally, the empirical work attested the significant impact that perceived usefulness had on perceived value for loT enabled services. In other words, citizens strongly believe that loT technologies are useful and are creating value for them. This has also been validated by Wang (2014) whose research confirmed that perceived usefulness has a positive effect on perceived value in innovative mobile technologies used within public services. Moreover, Hsu and Lin (2016) posit that ubiquitous interactions and content generation among users and their respective service providers can be the driving force behind the success of loT services. Our results also conform to previous studies by Liang et al. (2011) and Hajli et al (2015) who emphasised on the importance of informational social support in contributing positively towards influencing continued use intentions.

Overall, this study offers new insights on understanding what entices citizens - as loT adopters to continue to use IoT enabled services offered by the public sector. It highlights the influence that value has on the decision that citizens make to continue using technical innovations such as IoT when applied in the context of services offered by the public sector. In other words, 
citizens who feel that using loT facilitated services is compatible with their values and beliefs are more likely to adopt such services (Hsu and Lin, 2016). In this respect, our study demonstrates how loT capabilities can offer an opportunity for governments and relevant service providers to help enhance citizens' engagement and participation with public services. The study argued that with the right enabling technologies and applications, loT can transform citizens' engagement from 'passive' and/or 'consumers' of public sector information towards a more ubiquitously 'active', and/or 'contributors' of information within their communities. In other words, the dynamics of IoT technologies, supported by the wider use of enabled devices and associated services can clearly contribute positively towards demonstrating to citizens the value of utilising these technologies as part of their daily life activities. As a result, this enables the realisation of how these seamless technologies can contribute towards empowering citizens to be more proactively involved in exploiting the full and impactful use of key public services such as transport, education, healthcare and domestic utilities in a manner that would benefit not only themselves but the wider society. In this way, citizens become ubiquitous and proactive contributors of information into a wider public services eco-system that can be shared and used by others. However, based on the observations made in this research, we posit that most citizens are currently 'consumers' of loT for personal and routine day to day life events rather than proactive contributors to the wider public service eco-system. Therefore, the level of maturity of loT use in the public sector context still appears to be embryonic. Based on the learnings from our study, in Figure 3 we propose a representative model of how the maturity of citizens' engagement with public services will evolve through the use of IoT technologies. 
Level of Maturity

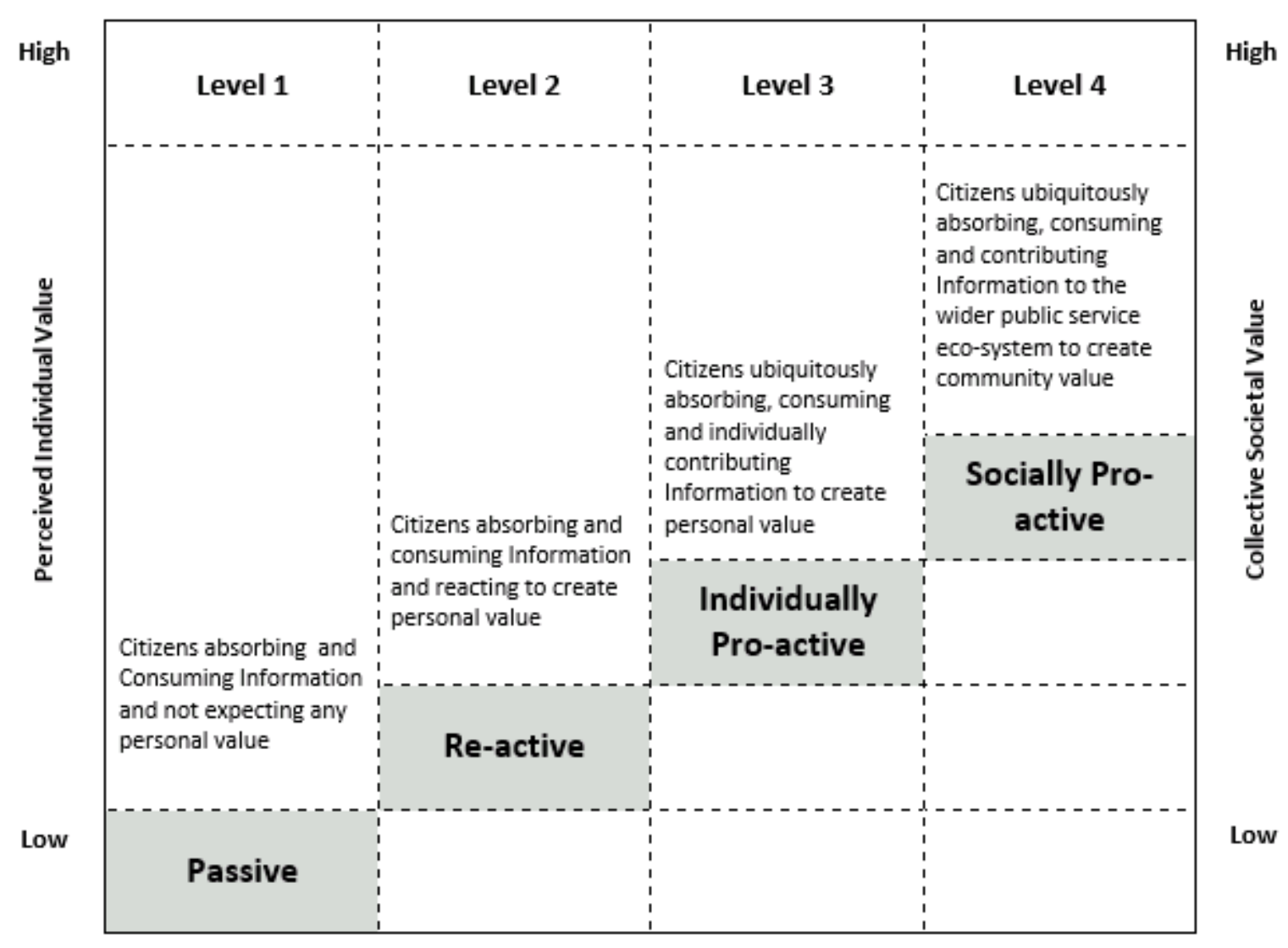

Level of Engagement

Figure 3: Perspective Maturity Model for Citizens' Use of IoT Technologies in the Public Sector

Although the citizens surveyed in our study in the UK appear to use loT enabled technologies to interact with services offered by the public sector on a regular basis, general engagement with IoT in the UK is reported to be around 30 percent and expected to grow to 43 percent by 2020 (Statista, 2016). As illustrated in figure 3, we argue that both the individual value of loT for citizens and collective societal value will begin to rise only when the level of engagement moves from passive consumption for individual purposes to more ubiquitous engagement that creates value for the wider community. In other words, when a citizen consumes loT based information and simply shares it with others in its original form and/or contributes new information through IoT relating to a specific public service that will be of use to others, this is considered as 
societally proactive. In this context, IOT not only empowers citizens to ubiquitously and proactively engage with public services, compared to existing conventional channels such as an electronic government website, it also offers governments the opportunity to potentially improve its services by co-creating them with citizens.

\section{Conclusion}

The objective of this study is to understand the role of perceived value of IoT enabled public services in their continuous use intention. Drawing upon extant literature, this study derived a model for investigating citizens' use of IoT facilitated public services and the influence that perceived value has on continued use. The model was tested through an empirical study in the UK where data was collected from 313 users of IoT based public services. The obtained empirical results verified that the impact of perceived value is influenced by citizens' empowerment, information privacy, and perceived usefulness of loT within public services, which is, in turn, significantly impacting citizens' continuous use intention. Further, the outcomes of this empirical work demonstrated the significant direct and positive influence informational social support has on the citizens continuous use intentions.

This study provides useful insights to both research and practice regarding the use of loT among citizens in the context of public sector services. In particular, from an academic perspective, the study makes a valuable contribution in advancing the understanding of behavioural and social perceptions associated with utilising loT technologies. By examining the influence of perceived value and its associated antecedents towards realising citizens' continuous use intentions, this research has shed new light on how innovative and emergent technologies can play a pivotal role in the day-to-day lives of citizens. Indeed, our findings confirm that loT offers both citizens and governments the opportunity to engage and co-create public services in various spheres.

From a practical perspective, the findings of this study suggest that the service providers need to offer the necessary assurances to citizens relating to information privacy. Similarly, citizens will need to acknowledge that loT can help in developing a sense of empowerment, which can result in increasing their engagement levels towards a more proactive and mature role when interacting with public services. From a policy perspective, this study offers a reference point to 
governments and services providers in terms of capturing the citizens' perspective on loT diffusion and use strategies. The findings also offer governments and loT service providers some insights on how loT enabled technologies can be utilised to further support the increased use and participation of citizens as contributors and 'value adders' of information to the public service eco-system. While extending the understanding of adoption and use of loT enabled public service, this study also highlighted that citizens engagement with loT enabled public services is yet to mature and several challenges remain to be addressed. As such more work needs to be done in terms of raising awareness of the perceived value of IoT technologies in order to enhance the level of citizens engagement (i.e. from passive consumers to proactive contributors). This will ensure evolution of the maturity of IoT based public services as depicted in the proposed loT maturity model in Figure 3. Nonetheless, despite such challenges, loT offers a unique opportunity to both governments and citizens to work closely together to enhance current public services. While citizens feel empowered and as a result are enticed to add value to existing services through consuming and co-creating, governments will have the opportunity to fully exploit the potential of innovative technologies to better optimise their delivery of public services.

As with other research, this study has some limitations. The survey sample covered one country; the United Kingdom. This may limit the generalisability of the findings and may not be considering other countries. In this context, future research should aim to target citizens in other countries to perform a cross-comparison of IoT continuous use intentions among citizens. Nevertheless, the unit of analysis of this study was not focused on cross cultural perspective, but rather on citizens' perspective and behaviour towards loT use in public sector services. Generalisations from this research should be made with caution. In addition to the existing body of knowledge on adoption of innovative technologies in public sector, the research model proposed in this study captures four key factors and how they individually affect continuous use of IoT technologies. While this is a modest contribution to IS/IT adoption and use in the public sector domain, this study has nevertheless addressed a real research gap that exist in the IS/IT literature in relation to the emerging paradigm of IoT especially in this context. 


\section{References}

1. Al-Ali, A.R., Zualkernan, I. and Aloul, F., 2010. A mobile GPRS-sensors array for air pollution monitoring. IEEE Sensors Journal, 10(10), pp.1666-1671.

2. Albino, V., Berardi, U. and Dangelico, R.M., 2015. Smart cities: Definitions, dimensions, performance, and initiatives. Journal of Urban Technology, 22(1), pp.3-21.

3. Ajzen, I. and Fishbein, M., 1975. Belief, attitude, intention and behavior: An introduction to theory and research.

4. Atzori, L., lera, A., \& Morabito, G. 2010. The internet of things: a survey. Computer Networks, 54(15), 2787-2805.

5. Bandura, A., 1977. Self-efficacy: toward a unifying theory of behavioral change. Psychological review, 84(2), p.191.

6. Bagozzi, R.P. and Dholakia, U.M., 2006. Antecedents and purchase consequences of customer participation in small group brand communities. International Journal of research in Marketing, 23(1), pp.45-61.

7. Bagozzi, R.P. \& Yi, Y. 1988. On the evaluation of structural equation models, Journal of the Academy of Marketing Science, Volume 16, Issue 1, pp 74-94

8. Barcena, M. and Wueest, C. "Insecurity in the Internet of Things," Symantec, March 2015

9. Belissent, J., 2011. Getting clever about smart cities: new opportunities require new business models, Forrester Research, 2010. Gartner's hype cycle special report.

10. Bonomi, F., Milito, R., Zhu, J. and Addepalli, S., 2012, August. Fog computing and its role in the internet of things. In Proceedings of the first edition of the MCC workshop on Mobile cloud computing (pp. 13-16). ACM.

11. Boulos, M.N.K. and Al-Shorbaji, N.M., 2014. On the Internet of Things, smart cities and the WHO Healthy Cities. International journal of health geographics, 13(1), p.10.

12. Bryman, A. and Bell, E. 2011. Business Research Methods 3rd edn, Oxford: Oxford university press.

13. Cao, T.D., Hoang, H.H., Huynh, H.X., Nguyen, B.M., Pham, T.V., Tran-Minh, Q., Tran, V.T. and Truong, H.L., 2016. IoT Services for Solving Critical Problems in Vietnam: A Research Landscape and Directions. IEEE Internet Computing, 20(5), pp.76-81.

14. Chan, S.C. and Lu, M.T., 2004. Understanding Internet banking adoption and user behavior: A Hong Kong perspective.

15. Chen, C.F. and Chen, F.S., 2010. Experience quality, perceived value, satisfaction and behavioral intentions for heritage tourists. Tourism management, 31(1), pp.29-35.

16. Choi, J. and Kim, S., 2016. Is the smartwatch an IT product or a fashion product? A study on factors affecting the intention to use smartwatches. Computers in Human Behavior, 63, pp.777-786.

17. Collis, J. and Hussey, R. 2014. Business research: a practical guide for undergraduate and postgraduate students 4th edn, Basingstoke: Palgrave Macmillan.

18. Conrad Henry, P. and Caldwell, M., 2006. Self-empowerment and consumption: Consumer remedies for prolonged stigmatization. European Journal of Marketing, 40(9/10), pp.1031-1048.

19. Cretu, L.G., 2012. Smart cities design using event-driven paradigm and semantic web. Informatica Economica, 16(4), p.57.

20. Dinev, T. and Hart, P., 2006. An extended privacy calculus model for e-commerce transactions. Information Systems Research, 17(1), pp.61-80.

21. Dodds, W.B., Monroe, K.B. and Grewal, D., 1991. Effects of price, brand, and store information on buyers' product evaluations. Journal of marketing research, pp.307-319. 
22. Enterprise, H.P., 2015. Internet of things research study. HP loT Research Study

23. Fang, X. W., Chan, S., Brzezinski, J., \& Xu, S. 2006. Moderating effects of task type on wireless technology acceptance. Journal of Management Information Systems, 22(3), 123-157.

24. Fishbein, M. and Ajzen, I., 1977. Belief, attitude, intention, and behavior: An introduction to theory and research.

25. Füller, J., Mühlbacher, H., Matzler, K. and Jawecki, G., 2010. Consumer empowerment through internet-based co-creation. Journal of Management Information Systems, 26(3), pp.71-102.

26. Gao, L. and Bai, X., 2014. A unified perspective on the factors influencing consumer acceptance of internet of things technology. Asia Pacific Journal of Marketing and Logistics, 26(2), pp.211-231.

27. Gefen, D., 2002. Reflections on the dimensions of trust and trustworthiness among online consumers. ACM Sigmis Database, 33(3), pp.38-53.

28. Gunashekar, S, Spisak, A., Dean, K., Ryan, N., Lepetit, L. and Cornish, P. 2016 Accelerating the Internet of Things in the UK: Using policy to support practice. Santa Monica, CA: RAND Corporation, https://www.rand.org/pubs/research reports/RR1492.html. Last accessed September 2017

29. Reaidy, P. J., A. Gunasekaran, and A. Spalanzani. 2015. "Bottom-up Approach Based on Internet of Things for Order Fulfillment in a Collaborative Warehousing Environment." International Journal of Production Economics 159: 29-40.

30. Hair, J.F., Tatham, R.L., Anderson, R.E. and Black, W. 2006. Multivariate data analysis. Pearson Prentice Hall, Upper Saddle River, NJ.

31. Hair, J.F., Black, W. C., Babin, B.J. and Anderson, R.E. 2010. Multivariate data analysis, 7th edn. Pearson, New York

32. Hajli, N., 2015. Social commerce constructs and consumer's intention to buy. International Journal of Information Management, 35(2), pp.183-191.

33. Hajli, N., Shanmugam, M., Powell, P. and Love, P.E., 2015. A study on the continuance participation in on-line communities with social commerce perspective. Technological Forecasting and Social Change, 96, pp.232-241.

34. Hajli, N. and Lin, X., 2016. Exploring the security of information sharing on social networking sites: The role of perceived control of information. Journal of Business Ethics, 133(1), pp.111-123.

35. Harrison, C., Eckman, B., Hamilton, R., Hartswick, P., Kalagnanam, J., Paraszczak, J. and Williams, P., 2010. Foundations for smarter cities. IBM Journal of Research and Development, 54(4), pp.1-16.

36. Hinton, P. R., Brownlow, C., McMurray, I. and Cozens, B. (2004). SPSS explained. Routledge Inc. East Sussex, England.

37. Hsu, C.L. and Lin, J.C.C., 2016. An empirical examination of consumer adoption of Internet of Things services: Network externalities and concern for information privacy perspectives. Computers in Human Behavior, 62, pp.516-527.

38. Hsu C. and Yeh C. 2017. Understanding the factors affecting the adoption of the Internet of Things, Technology Analysis \& Strategic Management, 29(9), 1089-1102

39. Huang, K.Y., Nambisan, P. and Uzuner, Ö., 2010, December. Informational Support or Emotional Support: Preliminary Study of an Automated Approach to Analyze Online Support Community Contents. In ICIS (p. 210).

40. Hwang, Y., Kim, M. and Rho, J. 2016. "Understanding internet of things (IoT) diffusion focusing on value configuration of RFID and sensors in business cases (2008-2012)", Information Development, 32(4). 969-985

41. Jain, V., Gupta, S. and Ahuja, T., 2016, August. Monitoring the odd-even car rationing scheme phase 2.0 in Delhi. In Proceedings of the International Conference on Informatics and Analytics (p. 7). ACM.

42. Jin, J., Gubbi, J., Marusic, S. and Palaniswami, M., 2014. An information framework for creating a smart city through internet of things. IEEE Internet of Things Journal, 1(2), pp.112-121. 
43. Kim, T., Ramos, C., Mohammed, S. (2017) Smart City and IoT, Future Generation Computer Systems, 76, 159-162

44. Kim, H.W., Chan, H.C. and Gupta, S., 2007. Value-based adoption of mobile internet: an empirical investigation. Decision support systems, 43(1), pp.111-126.

45. Kshetri, N., 2017. The economics of the Internet of Things in the Global South. Third World Quarterly, 38(2), pp.311-339.

46. Kowatsch, T. and Maass, W., 2012. Critical privacy factors of internet of things services: an empirical investigation with domain experts. In Knowledge and Technologies in Innovative Information Systems (pp. 200-211). Springer, Berlin, Heidelberg.

47. Lee,I. and Lee, K. 2015. The Internet of Things (IOT): Applications, investments, and challenges for enterprises, In Business Horizons, 58(4), 431-440.

48. Lheurex, et al, Survey Analysis: Users Cite Ambitious Growth and formidable Technical Challenges in IoT Adoption, Gartner Report \#G00300127, March 2016,

49. Li, X., Shu, W., Li, M., Huang, H.Y., Luo, P.E. and Wu, M.Y., 2009. Performance evaluation of vehiclebased mobile sensor networks for traffic monitoring. IEEE transactions on vehicular technology, 58(4), pp.1647-1653.

50. Liang, T.P., Ho, Y.T., Li, Y.W. and Turban, E., 2011. What drives social commerce: The role of social support and relationship qu ality. International Journal of Electronic Commerce, 16(2), pp.69-90.

51. Lu, J., Yu, C.S., Liu, C. and Yao, J.E., 2003. Technology acceptance model for wireless Internet. Internet Research, 13(3), pp.206-222.

52. Maisonneuve, Nicolas, Matthias Stevens, Maria E. Niessen, Peter Hanappe, and Luc Steels. 2009. "Citizen noise pollution monitoring." In Proceedings of the 10th Annual International Conference on Digital Government Research: Social Networks: Making Connections between Citizens, Data and Government, pp. 96-103. Digital Government Society of North America.

53. Mahalle, P.N., Anggorojati, B., Prasad, N.R. and Prasad, R., 2013. Identity authentication and capability based access control (iacac) for the internet of things. Journal of Cyber Security and Mobility, 1(4), pp.309-348.

54. Malhotra, N.K., Kim, S.S. and Agarwal, J., 2004. Internet users' information privacy concerns (IUIPC): The construct, the scale, and a causal model. Information systems research, 15(4), pp.336-355.

55. McDermid, D., 2015. Ethics in ICT: an Australian perspective. Pearson Higher Education AU.

56. Mineraud, J., Mazhelis, O., Su, X. and Tarkoma, S., 2016. A gap analysis of Internet-of-Things platforms. Computer Communications, 89, pp.5-16.

57. Misra, P., Simmhan, Y. and Warrior, J. 2015. Towards a Practical Architecture for Internet of Things: An India-centric View. IEEE Internet of Things

58. Mital, M., Chang, V., Choudhary, P., Papa, A., Pani, A. 2017. Adoption of Internet of Things in India: A test of competing models using a structured equation modeling approach, Technological Forecasting and Social Change, In press

59. Olubiyo, S.O. and Oriade, A., 2017. The rural business environment in developing economies. Rural Tourism and Enterprise: Management, Marketing and Sustainability, p.86.

60. Omar, A., Weerakkody, V., Sivarajah, U. 2017. Digitally enabled service transformation in UK public sector: A case analysis of universal credit, In International Journal of Information Management, 37(4), 350-356,

61. Pavlou, P.A. and Chai, L., 2002. What drives electronic commerce across cultures? Across-cultural empirical investigation of the theory of planned behavior. J. Electron. Commerce Res., 3(4), pp.240253.

62. Pavlou, P.A., 2003. Consumer acceptance of electronic commerce: Integrating trust and risk with the technology acceptance model. International journal of electronic commerce, 7(3), pp.101-134. 
63. Penza, M., Suriano, D., Villani, M.G., Spinelle, L. and Gerboles, M., 2014, November. Towards air quality indices in smart cities by calibrated low-cost sensors applied to networks. In SENSORS, 2014 IEEE (pp. 2012-2017). IEEE.

64. Perera, C., Zaslavsky, A., Christen, P. and Georgakopoulos, D., 2014. Sensing as a service model for smart cities supported by internet of things. Transactions on Emerging Telecommunications Technologies, 25(1), pp.81-93.

65. Peterson, D.K., 2012. The Colbert bump ${ }^{\circledR}$ and The Facebook ${ }^{\circledR}$ follow-through for generation snark: A test and extension of The Ajzen's theory of planned behavior for 2012. Journal of Management Research, 4(3), p.43.

66. Porter, C.E. and Donthu, N., 2008. Cultivating trust and harvesting value in virtual communities. Management Science, 54(1), pp.113-128.

67. Prayoga, T. and Abraham, J., 2016. Behavioral Intention to Use loT Health Device: The Role of Perceived Usefulness, Facilitated Appropriation, Big Five Personality Traits, and Cultural Value Orientations.

68. Pura, M., 2005. Linking perceived value and loyalty in location-based mobile services. Managing Service Quality: An International Journal, 15(6), pp.509-538.

69. Sanchez, L., Muñoz, L., Galache, J.A., Sotres, P., Santana, J.R., Gutierrez, V., Ramdhany, R., Gluhak, A., Krco, S., Theodoridis, E. and Pfisterer, D., 2014. SmartSantander: IoT experimentation over a smart city testbed. Computer Networks, 61, pp.217-238.

70. Son, J.Y. and Kim, S.., 2008. Internet users' information privacy-protective responses: A taxonomy and a nomological model. MIS Quarterly, pp.503-529.

71. Spreitzer, G.M., 1995. Psychological empowerment in the workplace: Dimensions, measurement, and validation. Academy of management Journal, 38(5), pp.1442-1465.

72. Sun, H., and Zhang, P. (2006) "The role of moderating factors in user technology Acceptance", International Journal of Human-Computer Studies (IJHCS), vol. 64, no. 2, pp.53-78.

73. Taylor, S. and Todd, P. A. (1995) "Understanding Information Technology Usage: A Test of Competing Models", Information Systems Research, vol. 6, no. 2, pp. 144- 176.

74. Thakker, D., Dimitrova, V., Cohn, A.G. and Valdes, J., 2015, May. PADTUN-using semantic technologies in tunnel diagnosis and maintenance domain. In European Semantic Web Conference (pp. 683-698). Springer, Cham.

75. The Government Office for Science. 2014, The Internet of Things: Making The Most of The Second Digital Revolution. https://www.gov.uk/government/uploads/system/uploads/attachment data/file/409774/14-1230internet-of-things-review.pdf. Last accessed September 2017

76. Tiu Wright, L., Newman, A. and Dennis, C., 2006. Enhancing consumer empowerment. European Journal of Marketing, 40(9/10), pp.925-935.

77. Valtonen, T., Kukkonen, J., Kontkanen, S., Sormunen, K., Dillon, P. and Sointu, E., 2015. The impact of authentic learning experiences with ICT on pre-service teachers' intentions to use ICT for teaching and learning. Computers \& Education, 81, pp.49-58.

78. Waller, P., \& Weerakkody, V. (2016). Digital government: Overcoming the systemic failure of transformation. Working paper 2

79. Wang, C. 2014. Antecedents and consequences of perceived value in mobile government continuance use: An empirical research in China. Computers in Human Behavior, 34, 140-147.

80. Wang, C., Chen, G., Dong, R. and Wang, H., 2013. Traffic noise monitoring and simulation research in Xiamen City based on the Environmental Internet of Things. International Journal of Sustainable Development \& World Ecology, 20(3), pp.248-253. 
81. Wang, S., Zhang, Z., Ye, Z., Wang, X., Lin, X. and Chen, S., 2013. Application of environmental internet of things on water quality management of urban scenic river. International Journal of Sustainable Development \& World Ecology, 20(3), pp.216-222.

82. Weber, R.H., 2009. Internet of things-Need for a new legal environment?. Computer law \& security review, 25(6), pp.522-527.

83. Whitmore, A., Agarwal, A. and Da Xu, L., 2015. The Internet of Things-A survey of topics and trends. Information Systems Frontiers, 17(2), pp.261-274.

84. Xue, M., Li, D.C. and Shen, X.L., 2012. Construction of Smart Drainage System Based on Internet of Things. China Water \& Wastewater, 28(6), pp.62-64.

85. Yang, G., Xie, L., Mäntysalo, M., Zhou, X., Pang, Z., Da Xu, L., Kao-Walter, S., Chen, Q. and Zheng, L.R., 2014. A health-iot platform based on the integration of intelligent packaging, unobtrusive biosensor, and intelligent medicine box. IEEE transactions on industrial informatics, 10(4), pp.21802191.

86. Yang, Z. and Peterson, R.T., 2004. Customer perceived value, satisfaction, and loyalty: The role of switching costs. Psychology \& Marketing, 21(10), pp.799-822.

87. Venkatesh, V., Thong, J.Y.L., Chan, F.K.Y., Hu, P.J. and Brown, S.A. (2011) "Extending the two-stage information systems continuance model: incorporating UTAUT predictors and the role of context", Information Systems Journal, Vol. 21, pp. 527-555.

88. Yousafzai, S.Y., Foxall, G.R. and Pallister, J.G., 2010. Explaining internet banking behavior: Theory of reasoned action, theory of planned behavior, or technology acceptance model?. Journal of applied social psychology, 40(5), pp.1172-1202.

89. Zanella, A., Bui, N., Castellani, A., Vangelista, L. and Zorzi, M., 2014. Internet of things for smart cities. IEEE Internet of Things journal, 1(1), pp.22-32. 


\section{Appendix}

\begin{tabular}{|c|c|c|}
\hline & Constructs with Items & Sources \\
\hline \multicolumn{3}{|c|}{ Perceived Value } \\
\hline PV1 & $\begin{array}{l}\text { Compared to the effort I need to put in, the usage of loT Smart devices to collect and use } \\
\text { real time information is beneficial to me }\end{array}$ & \multirow{3}{*}{ Kim et al (2007) } \\
\hline PV2 & $\begin{array}{l}\text { Compared to the time I need to spend, the usage of IoT Smart devices to collect and use } \\
\text { real time information to interact with public sector services is worthwhile to me }\end{array}$ & \\
\hline PV3 & $\begin{array}{l}\text { Overall, the usage of IoT Smart devices to collect and use real time information and } \\
\text { services provided by the public sector delivers good value for me }\end{array}$ & \\
\hline \multicolumn{3}{|c|}{ Information Privacy } \\
\hline IP1 & IoT service providers should not sell my personal information to other companies & \multirow{5}{*}{ Hsu and Lin (2016) } \\
\hline IP2 & $\begin{array}{l}\text { loT service providers should not share my personal information with other companies } \\
\text { unless I specifically authorized to do so }\end{array}$ & \\
\hline IP3 & $\begin{array}{l}\text { loT service providers should not use my personal information for any purpose not } \\
\text { specifically authorized by me }\end{array}$ & \\
\hline IP4 & IoT service providers should prevent any unauthorized access to my personal information & \\
\hline IP5 & $\begin{array}{l}\text { loT service providers should take more steps to ensure that my personal information on } \\
\text { their systems is accurate }\end{array}$ & \\
\hline \multicolumn{3}{|c|}{ Perceived Usefulness } \\
\hline PU1 & $\begin{array}{l}\text { Using loT smart devices to collect and use real time information when interacting with } \\
\text { public sector services enhances the overall productivity of my daily activities }\end{array}$ & \multirow{3}{*}{$\begin{array}{l}\text { Gao and Bai (2014); } \\
\text { Mitalaa et al (2016); Su } \\
\text { and Han (2002) }\end{array}$} \\
\hline PU2 & $\begin{array}{l}\text { Using loT smart devices to collect real time information when interacting with public } \\
\text { sector services enable me to accomplish my daily activities more quickly }\end{array}$ & \\
\hline PU3 & $\begin{array}{l}\text { Overall, I find loT smart devices to collect real time information when interacting with } \\
\text { public sector services to be advantageous }\end{array}$ & \\
\hline \multicolumn{3}{|c|}{ Empowerment } \\
\hline E1 & $\begin{array}{l}\text { I feel enthused to actively use loT smart devices to collect real time information when } \\
\text { interacting with public sector services }\end{array}$ & \multirow{2}{*}{ Füller et al (2010) } \\
\hline E2 & $\begin{array}{l}\text { Using loT smart devices to collect real time information when interacting with public } \\
\text { sector services gives me a feeling of accomplishment }\end{array}$ & \\
\hline$E 3^{1}$ & $\begin{array}{l}\text { With the use of loT smart devices and associated applications I am able to manage my } \\
\text { everyday life activities better }\end{array}$ & \\
\hline \multicolumn{3}{|c|}{ Informational Social Support } \\
\hline IFS1 & $\begin{array}{l}\text { Some people with knowledge and experience of using loT smart devices, collecting real } \\
\text { time information, offer suggestions when I need help using them to collect and use real } \\
\text { time information for public sector services }\end{array}$ & \multirow{3}{*}{ Hajli et al (2015) } \\
\hline IFS2 & $\begin{array}{l}\text { When I encounter a problem with loT using smart devices for collecting real time } \\
\text { information in public sector services, some people with knowledge about these } \\
\text { technologies offer information to help me overcome the problem }\end{array}$ & \\
\hline IFS3 & $\begin{array}{l}\text { When faced with difficulties with loT smart devices to collect real time information in } \\
\text { public sector services, some people with knowledge about these technologies help me } \\
\text { discover the cause and provide me with suggestions }\end{array}$ & \\
\hline \multicolumn{3}{|c|}{ Continued Usage Intentions } \\
\hline CUI1 & $\begin{array}{l}\text { I intend to continue using loT smart devices to collect and/or engage with real time when } \\
\text { interacting with public sector services rather than discontinue their use }\end{array}$ & \multirow{3}{*}{$\begin{array}{l}\text { Hajli et al (2015); Liang et } \\
\text { al (2011) }\end{array}$} \\
\hline CUI2 & $\begin{array}{l}\text { I will continue using loT smart devices to collect and/or engage with real time when } \\
\text { interacting with public sector services in the future }\end{array}$ & \\
\hline CUI3 & $\begin{array}{l}\text { I will regularly use loT smart devices to collect and/or engage with real time when } \\
\text { interacting with public sector services in the future }\end{array}$ & \\
\hline
\end{tabular}

\footnotetext{
${ }^{1}$ E3 Item was removed based on insignificant factor loading measure
} 